\title{
HUBUNGAN KEBIASAAN OLAHRAGA DENGAN DISMENORE PRIMER PADA REMAJA PUTRI DI SMA NEGERI 04 BANDA ACEH TAHUN 2014
}

\author{
Fithriany*, Ulfa Amelia** \\ Jurusan Kebidanan Politeknik Kesehatan Kemenkes Aceh
}

\begin{abstract}
Dismenorrhea is menstrual pain that is felt in the lower abdomen and radiates up into the pelvis that can interfere with daily activities. Regular exercise can reduce stress and fatigue that can indirectly reduce pain. Prevalence of dismenorrhea in Indonesia (2008) amounted to 64,25\%, consisting of 54,89\% primary dismenorrhea and 98,5\% secondary dismenorrhea. The purpose of this study was to determine the relation of primary dismenorrhea with the regular exercise at Senior High School 04 Banda Aceh. This research conducted since April to July. This was analitic study by using Cross Sectional design. There were 307 students in grade 1 and 2 as the population and the sampling method used Purposive Sampling as 75 respondents. The proportion of respondents who do exercise regulary (37,3\%) of 28 respondents and who do not exercise regulary $(62,7 \%)$ as many as 47 respondents. The proportion of primary dismenorrhea which felt by respondents, 42,67\% of respondents had mild pain (32 respondents), 36,0\% of respondents had moderate pain (27 respondents) and 21,3\% of respondents had severe pain (16 respondents). Chi-Square test was conducted as analysis method with $p<0,05$. The result of this research found that there was a relation of primary dismenorrhea with the regular exercise of students at Senior High School 04 Banda Aceh and obtained value $p=0,043(p<0,05)$.
\end{abstract}

Keywords : Primary dismenorrhea, regular exercise

\section{PENDAHULUAN}

Masa remaja adalah masa peralihan dari masa kanak-kanak menuju masa dewasa, dimana pada masa itu terjadi pertumbuhan yang sangat pesat termasuk fungsi reproduksi sehingga mempengaruhi akan terjadinya perubahan-perubahan perkembangan, baik fisik, mental, maupun peran sosial. Remaja adalah usia dimana anak tidak merasa bahwa dirinya berada dibawah tingkat orang yang lebih tua melainkan merasa sama atau paling tidak sejajar (Kumalasari dan Andhyantoro, 2012).

Menurut Nita (2008) dalam Fajaryati (2011) menyatakan setiap remaja akan mengalami pubertas. Pubertas merupakan masa awal pematangan seksual, yakni suatu periode dimana seorang anak mengalami perubahan fisik, hormonal, dan seksual serta mampu mengadakan proses reproduksi. Pada awal masa pubertas, kadar hormon LH (luteinizinghormone) dan FSH (follicle-stimulating hormone) akan meningkat, sehingga merangsang pembentukan hormon seksual. Pada remaja putri, peningkatan kadar hormon tersebut menyebabkan pematangan payudara, ovarium, rahim, dan vagina serta dimulainya siklus menstruasi.

Menstruasi pada setiap wanita itu berbeda-beda. Ada wanita yang menstruasi tanpa masalah dan gangguan apa-apa tetapi ada juga yang bermasalah dari yang biasa sampai yang harus dibawa kedokter karena menstruasi yang dialaminya dapat mengganggu aktivitas sampai tidak bisa melakukan aktivitas seperti biasa karena gangguan yang dialami dalam menstruasi yang sering disebut dismenore (Asrinah, Syarifah, dan Suciyanti, 2011). Kelainan atau gangguan yang ada hubungan dengan menstruasi diantaranya premenstrual tension (ketegangan sebelum haid), mastodinia, mittelschmerz (rasa nyeri saat ovulasi) dan dismenore (rasa nyeri saat menstruasi) (Manuaba, 1999 dalam Fajaryati, 2011).

Dismenore adalah nyeri haid yang biasanya bersifat kram dan berpusat pada perut bagian bawah yang terasa sebelum atau selama menstruasi, terkadang jika berat akan mengganggu aktivitas. (Ganon, 1986 dalam Sophia, Muda, dan Jemadi, 2013).

Angka kejadian dismenore pada tahun 2005 sebanyak $75 \%$ remaja wanita di Mesir mengalami dismenore, $55,3 \%$ dismenore ringan, $30 \%$ dismenore sedang, dan 14,8\% dismenore berat. (Badawi, 2005 dalam Sophia, et al, 2013) Pada tahun yang sama di Jepang angka kejadian dismenore primer 46\%. (Osuga, 2005 dalam Sophia, et al, 2013) Pada tahun 2010 di china angka kejadian dismenore primer sekitar 41,9\%-79,4\%. (Guizhou, 2010 dalam Sophia, et al, 2013) Pada tahun 2012 pravelensi dismenore primer di Amerika Serikat adalah 59,7\%. (Omidvar, 2012 dalam Sophia, et al, 2013). Sedangkan Pravelensi dismenore di Indonesia tahun 2008 sebesar 64,25\% yang terdiri dari 54,89\% dismenore primer dan 9,36\% dismenore sekunder. (Santoso, 2008 dalam Sophia, et al, 2013) Pada tahun 2010 di Manado 98,5\% siswi SMP mengalami dismenore, 94,5\% mengalami nyeri 
ringan, sedangkan nyeri sedang dan berat 3,5\% dan $2 \%$. (Lestari, 2010 dalam Sophia, et al, 2013)

Menurut Proverawati dan Misaroh (2009) dalam Fajaryati (2011) menyatakan latihan olahraga mampu meningkatkan produksi endorphin (pembunuh rasa sakit alami tubuh), dapat meningkatkan kadar serotonin. Latihan olahraga yang teratur dapat menurunkan stress dan kelelahan sehingga secara tidak langsung mengurangi nyeri. Membiasakan olahraga ringan dan aktivitas fisik secara teratur seperti jalan sehat, berlari, bersepeda, ataupun berenang pada saat sebelum dan selama haid, hal tersebut dapat membuat aliran darah pada otot sekitar rahim menjadi lancar, sehingga rasa nyeri dapat teratasi atau berkurang. Latihan ini sedikitnya 30-60 menit dengan frekuensi 3-5 kali seminggu.

Berdasarkan hasil penelitian ternyata dismenore primer lebih sedikit terjadi pada wanita yang berolahraga dibandingkan wanita yang tidak melakukan olahraga / senam. (Sumudarsono, 1998 dalam Fajaryati, 2011).

Hasil studi pendahuluan yang pertama dilakukan pada tanggal 13 Maret 2014 dengan metode wawancara kepada 15 siswi kelas 1 dan 2 di SMA N 04 Banda Aceh didapatkan 13 siswi yang mengalami nyeri haid dan 2 siswi yang tidak mengalami nyeri haid. Hasil studi pendahuluan yang kedua dilakukan pada tanggal 17 Maret 2014 dengan metode wawancara kepada 15 siswi kelas 1 dan 2 di SMA N 1 Krueng Barona Jaya Aceh Besar didapatkan 10 siswi yang mengalami nyeri haid dan 5 siswi yang tidak mengalami nyeri haid. Baik siswi yang mengalami maupun yang tidak mengalami nyeri haid mengatakan melakukan olahraga minimal satu kali setiap minggu yang merupakan pelajaran wajib di sekolah.

Meskipun teori tentang olahraga (jalan sehat, berlari, bersepeda, ataupun berenang) dapat menurunkan dismenore sudah ada, tetapi masih terbatasnya pembuktian ilmiah tentang teori tersebut, sehingga penulis tertarik untuk mengangkat masalah tersebut dengan judul "Hubungan Kebiasaan Olahraga Dengan Dismenore Primer Remaja Putri Di SMA Negeri 04 Banda Aceh Tahun 2014".

\section{METODELOGI PENELITIAN}

Penelitian yang digunakan adalah analitik dengan menggunakan pendekatan cross sectional yang dilakukan sejak tanggal 11 April s/d 14 Juli 2014 di SMA Negeri 04 Banda Aceh. Populasi dalam penelitian ini adalah seluruh siswi kelas 1 dan 2 SMA Negeri 04 Banda Aceh yang berjumlah 307 orang. Pengambilan sampel menggunakan teknik Purposive Sampling. Besarnya sampel dalam penelitian ini dihitung menggunakan rumus Slovin sebagai berikut:

$$
\begin{aligned}
& \mathrm{n}=\frac{\mathrm{N}}{1+\mathrm{N}\left(\mathrm{d}^{2}\right)} \\
& \mathrm{n}=\frac{307}{1+307\left(0,10^{2}\right)}
\end{aligned}
$$

$$
\begin{gathered}
\mathrm{n}=\frac{307}{1+307(0,01)} \\
\mathrm{n}=\frac{307}{4,07} \\
\mathrm{n}=75,42=75 \text { orang }
\end{gathered}
$$

Dengan keterangan:

$$
\begin{array}{ll}
\mathrm{n} & =\text { Ukuran sampel } \\
\mathrm{N} & =\text { Ukuran populasi } \\
\mathrm{d} & =\text { Presisi atau ketepatan atau batas }
\end{array}
$$

Kriteria inklusi dalam penelitian ini adalah:

a. Remaja yang mengalami nyeri haid pada hari 1-3

b. Remaja yang mengalami dismenore primer yang bersedia menjadi responden

Instrumen yang digunakan dalam penelitian ini berupa kuesioner yang berisi 10 pertanyaan terbuka dengan bentuk multiple choise yang terdiri dari 5 pertanyaan tentang dismenore, dan 5 pertanyaan tentang olahraga.

Setelah dilakukan pengolahan data maka analisis data dilakukan dengan melakukan program komputer yaitu program Statistical Product and Service Solutions (SPSS) yang dilakukan secara statistic analitik. Untuk menguji hipotesa dilakukan analisa statistic dengan menggunakan uji data chi- square test pada tingkat kemaknaan 95\% ( $\mathrm{P}<0,05)$, sehingga dapat diketahui ada tidaknya hubungan yang bermakna secara statistik. Selanjutnya ditarik kesimpulan bila $\mathrm{P}$ lebih kecil dari alpha $(\mathrm{P}<0,05)$ maka Ho ditolak dan $\mathrm{Ha}$ diterima, menunjukkan ada hubungan yang bermakna antara variabel dependen dengan variabel independen.

\section{HASIL PENELITIAN}

Berdasarkan hasil penelitian yang dilakukan di SMA Negeri 04 Banda Aceh terhadap 75 responden, maka diperoleh hasil sebagai berikut:

Tabel 1. Distribusi Frekuensi Aktivitas Olahraga Siswi SMA Negeri 04 Banda Aceh Tahun 2014

\begin{tabular}{cccc}
\hline No. & Olahraga & Jumlah & Persentase (\%) \\
\hline 1. & Teratur & 28 & 37,33 \\
2. & Tidak teratur & 47 & 62,67 \\
\hline & Jumlah & 75 & 100 \\
\hline
\end{tabular}

Sumber: Data Primer

Berdasarkan tabel 1 dari 75 orang responden sebagian besar frekuensi olahraga yang dilakukan secara tidak teratur yaitu $62,67 \%$ atau 47 siswi dan frekuensi olahraga yang dilakukan secara teratur yaitu $37,33 \%$ atau 28 siswi. 
Tabel 2. Distribusi Frekuensi Dismenore Primer Siswi SMA Negeri 04 Banda Aceh Tahun 2014

\begin{tabular}{cccc}
\hline No. & Dismenore Primer & Jumlah & Presentase (\%) \\
\hline 1. & Ringan & 32 & 42,67 \\
2. & Sedang & 27 & 36 \\
3. & Berat & 16 & 21,33 \\
\hline & Jumlah & 75 & 100 \\
\hline
\end{tabular}

Sumber: Data Primer

rdasarkan tabel 2 dari 75 orang responden sebagian besar frekuensi mengalami nyeri ringan yaitu $42,67 \%$ atau 32 siswi, frekuensi yang mengalami nyeri sedang yaitu $36 \%$ atau 27 siswi dan frekuensi yang mengalami nyeri berat $21,33 \%$ atau 16 siswi.

Tabel 3. Distribusi Hubungan Kebiasaan Olahraga dengan Dismenore Primer di SMA Negeri 04 Banda Aceh Tahun 2014

\begin{tabular}{|c|c|c|c|c|c|c|c|c|c|}
\hline \multirow{3}{*}{ Olahraga } & \multicolumn{6}{|c|}{ Dismenore Primer } & \multicolumn{2}{|c|}{ Total } & \multirow{3}{*}{$\begin{array}{c}P \\
\text { Value }\end{array}$} \\
\hline & \multicolumn{2}{|c|}{ Ringan } & \multicolumn{2}{|c|}{ Sedang } & \multicolumn{2}{|c|}{ Berat } & & & \\
\hline & $\mathbf{N}$ & $\%$ & $\mathbf{N}$ & $\%$ & $\mathbf{N}$ & $\%$ & $\mathbf{N}$ & $\%$ & \\
\hline Teratur & 17 & 60,7 & 6 & 21,4 & 5 & 17,9 & 28 & 100 & \\
\hline $\begin{array}{l}\text { Tidak } \\
\text { Teratur }\end{array}$ & 15 & 31,9 & 21 & 44,7 & 11 & 23,4 & 47 & 100 & 0,043 \\
\hline
\end{tabular}

Sumber: Data Primer

Berdasarkan tabel 3 diatas diperoleh hasil bahwa dari 28 siswi yang melakukan olahraga secara teratur 60,7 $\%$ mengalami dismenore ringan $21,4 \%$ yang mengalami dismenore sedang dan $17,9 \%$ mengalami dismenore berat. Sedangkan dari 47 siswi yang melakukan olahraga secara tidak teratur $23,4 \%$ mengalami dismenore berat $44,7 \%$ yang mengalami dismenore sedang dan 31,9\% mengalami dismenore ringan.

Hasil uji statistik dengan Chi-Square pada $\alpha=0,05$ didapatkan $P$ value 0,043 , sehingga memperlihatkan ada hubungan yang signifikan antara olahraga dengan kejadian dismenore primer.

\section{PEMBAHASAN}

Berdasarkan tabel 3 diperoleh hasil bahwa siswi yang melakukan olahraga secara teratur mempunyai skala nyeri ringan $(60,72 \%)$ yaitu sebanyak 17 siswi dan pada siswi yang melakukan olahraga secara tidak teratur mempunyai skala nyeri berat $(68,09 \%)$ yaitu sebanyak 32 siswi. Hal tersebut menunjukkan bahwa dengan berolahraga secara teratur maupun tidak teratur akan berpengaruh secara signifikan terhadap skala nyeri yang diderita oleh sebagian besar responden yang mengalami dismenore primer.

Hasil korelasi dengan menggunakan uji statistik Chi-Square didapatkan bahwa ada hubungan kebiasaan olahraga dengan dismenore primer dengan $\mathrm{P}$ $=0,043<\alpha=0,05$. Berdasarkan hasil penelitian diketahui bahwa faktor olahraga ternyata berpengaruh terhadap skala nyeri yang diderita oleh sebagian besar responden yang mengalami dismenore primer.
Hal tersebut sesuai dengan pendapat (Sumosardjuno (1988) dalam Fajaryati (2011)), dismenore primer yang dapat dikurangi dengan olahraga secara teratur di alam terbuka. Hal ini mungkin terjadi karena olahraga yang hanya berfungsi meningkatkan aliran darah seperti mekanisme stimultan adrenoreseptor sebagai obat dismenore primer atau memperbesar volume darah, belum cukup menyebabkan berkurangnya dismenore primer masih diperlukan jenis olahraga tertentu yang bias mengurangi faktor-faktor terjadinya dismenore primer atau yang mampu membawa penderita keadaan psikis atau somatis pada tingkat yang normal.

Menurut Prawirohardjo (2005), dismenore primer (disebut juga sebagai dismenore idiopatik, esensial, intrinsik) adalah nyeri haid yang dijumpai tanpa kelainan pada alat-alat genital yang nyata, atau tidak ada hubungan dengan kelainan ginekologik. Dismenore primer merupakan rasa sakit yang wajar dan biasa terjadi, disebabkan karena tingginya kadar prostaglandin atau zat yang membuat otot-otot rahim berkontraksi dan melepaskan dindingnya. Dismenore primer terjadi pada hari pertama sampai hari ketiga menstruasi.

Siswi yang mengalami dismenore primer menyatakan mereka minum obat untuk mengatasi nyeri haid / dismenore primer dibandingkan melakukan olahraga secara teratur untuk mengatasi nyeri haid. Obat yang mereka gunakan yaitu obat yang meredakan atau menghilangkan nyeri haid dengan lebih cepat. Obat-obatan yang digunakan harus atas pengawasan dokter. Obat yang boleh diminum yaitu analgetik (penghilang rasa sakit) yang banyak dijual di toko obat terutama yang mengandung antara lain asam mefenamat, ibuprofen (Dita, 2010 dalam Fajaryati, 2011). Untuk itu perlu adanya alternatif lain yang bersifat preventif untuk mengatasi dismenore primer. Olahraga yang dilakukan harus dilakukan secara teratur dan benar. Latihan ini tidak akan efisiensi atau kurang membuahkan hasil, kalau kurang dari takaran atau lebih dari takaran (Sumampow, 2010 dalam Fajaryati, 2011).

Adapun olahraga yang benar haruslah memenuhi kriteria frekuensi 3-5 kali seminggu dan lama 30-60 menit. Dari suatu penelitian telah disimpulkan bahwa latihan paling sedikit 3 kali perminggu, hal ini disebabkan ketahanan atau stamina seseorang akan menurun setelah 48 jam jika tidak melakukan latihan, jadi usahakan sebelum stamina menurun harus berlatih lagi (Sumosardjuno (1988) dalam Fajaryati, 2011).

Hasil penelitian ini juga sesuai dengan hasil penelitian yang dilakukan oleh Kundarti, et al (2012) yang menyatakan bahwa terdapat perbedaan tingkat dismenorhoe primer pada siswi yang rutin melakukan olahraga dan yang jarang melakukan olahraga. Siswi yang rutin melakukan olahraga mengalami tingkat dismenorhoe lebih ringan dibanding siswi yang jarang melakukan olahraga. 


\section{KESIMPULAN}

Berdasarkan hasil penelitian yang telah dilakukan pada Maret - Juli 2014 dengan judul Hubungan Kebiasaan Olahraga dengan Dismenore Primer pada Remaja Putri di SMA Negeri 04 Banda Aceh dapat disimpulkan bahwa terdapat hubungan kebiasaan olahraga dengan dismenore primer dengan menggunakan uji statistik chi-square didapatkan bahwa $\mathrm{P}=0,043(\mathrm{P}<0,05)$.

\section{DAFTAR PUSTAKA}

Abbaspour, Z. Rostami, M. dan Najjar, Sh. 2004. JournalThe Effect of Exercise on Primary Dysmenorrhea. J Res Health Sci : Iran

Asrinah. Jamingatu, S. dan Suciyanti. 2011. Menstruasi dan Permasalahannya. Pustaka Panasea : Tangerang

Fajaryati, Ninik. (2011). Jurnal Hubungan Kebiasaan Olahraga Dengan Dismenore Primer Remaja Putri Di SMP N 2 Mirit Kebumen.
Kumalasari, I. dan Andhyantoro, I. 2012. Kesehatan Reproduksi . Salemba Medika : Jakarta

Kundarti, F, I. Wijayanti, L, A. dan Astuti, W, W. (2012). Jurnal Perbedaan Tingkat Dismenorhoe Primer pada Siswi yang Rutin Melakukan Olahraga Di SMA $\quad N \quad 8 \quad$ Kota Kediri. Jurnal Penelitian Kesehatan Suara Forikes.

Kusmiran, Eny. 2011. Kesehatan Reproduksi Remaja dan Wanita. Salemba Medika : Jakarta

Prawirohardjo, S. 2005. Ilmu Kandungan. Jakarta: Yayasan Bina Pustaka

Ramaiah, S. 2006. Mengatasi Gangguan Menstruasi. Yogyakarta: Diglosia Medika.

Sophia, F. Muda S. dan Jemadi.(2013). Jurnal Faktorfaktor yang Berhubungan dengan Dismenore pada Siswi SMK N 10 Medan

Wijayanti, Daru. 2009. Fakta Penting Seputar Kesehatan Reproduksi Wanita. Diglossia Printika: Jogjakarta

Wiknjosastro, Hanifa. 1997. Ilmu Kandungan. Yayasan Bina Pustaka Sarwono Prawirohardjo: Jakarta. 